\title{
COMMUNICATION POLICY AS THE SOURCE OF CITIZENS' TRUST
}

\begin{abstract}
The article focuses on the national dimensions of the EU communication policy in Sweden, Finland and Denmark. The cornerstone of the EU communication policy is the dialogue with citizens about the policies and the future of the EU. It is based on openness, transparency and accountability which greatly contribute to building citizens' trust in the authorities' activity. EU communication policy is realized through e-governance, language policy and the policy in the sphere of mass media. The aim of the article is to analyze the experience and best practices of top 3 EU countries (Sweden, Finland and Denmark) in terms of the assessment of national policies in the field of ICT and digital skills of citizens in the sphere of communication policy. The hypothesis is that these states being the leaders as to citizens' digital literacy have introduced efficient channels of involving citizens in the decision making process.
\end{abstract}

\section{Key words}

communication policy, e-participation, language policy, participatory democracy

\section{Introduction}

Exploring the problem of the role of communication in the development of nations and peoples, Karl Deutsch concluded that "...the communication process is the basis of the cohesion of societies, cultures and even individuals" (Дойч,

* Natalia Karpchuk, PhD in Philology (Candidate of Philological Sciences), Associate Professor of International Information Department, International Relations Faculty in Lesya Ukrainka Eastern European National University, Lutsk, Ukraine. e-mail: karpchuknata@gmail.com. 